\title{
Multi-station basis for Polar Cap (PC) indices: ensuring credibility and operational reliability
}

\author{
Peter Stauning* \\ Danish Meteorological Institute (DMI), Lyngbyvej 100, 2100 Copenhagen, Denmark
}

Received 22 May 2017 / Accepted 23 November 2017

\begin{abstract}
The Polar Cap (PC) indices, PCN (North) and PCS (South) are based on polar geomagnetic observations from Qaanaaq (Thule) and Vostok, respectively, processed to measure the transpolar plasma convection that may seriously affect space weather conditions. To establish reliable space weather forecasts based on PC indices, and also to ensure credibility of their use for scientific analyses of solar windmagnetosphere interactions, additional sources of data for the PC indices are investigated. In the search for alternative index sources, objective quality criteria are established here to be used for the selection among potential candidates. These criteria are applied to existing PC index series to establish a quality scale. In the Canadian region, the data from Resolute Bay magnetometer are shown to provide alternative PCN indices of adequate quality. In Antarctica, the data from Concordia Dome-C observatory are shown to provide basis for alternative PCS indices. In examples to document the usefulness of these alternative index sources it is shown that PCN indices in a real-time version based on magnetometer data from Resolute Bay could have given $6 \mathrm{~h}$ of early warning, of which the last $2 \mathrm{~h}$ were "red alert", up to the onset of the strong substorm event on 13 March 1989 that caused power outage in Quebec. The alternative PCS indices based on data from Dome-C have helped to disclose that presently available Vostok-based PCS index values are corrupted throughout most of 2011.
\end{abstract}

Keywords: Space Weather / ionosphere (polar) / magnetosphere / solar wind / magnetic field

\section{Introduction}

The transpolar plasma convection over the magnetically open PCs presents a direct indication of the cross-PC electric fields created by the interaction of the solar wind with the Earth's magnetosphere that is considered responsible for major magnetic disturbances such as magnetic storms and substorms. At large altitudes the positive ions and the electrons are drifting together in this field and produce no net current. The drifting positive ions are stopped by collisions with the neutrals at heights around $100 \mathrm{~km}$ (E-region), while the electrons continue their drift further down thus providing a resulting electric current (Hall current) opposite of the convective drift. Hence, the convection intensity and direction could be monitored at ground level by observations of the transverse magnetic variations generated by the related ionospheric electric currents.

In order to provide a consistent measure of the transpolar convection, the PC index concept was proposed by Troshichev and Andrezen (1985) and further developed by Troshichev

\footnotetext{
*Corresponding author: pst@dmi.dk
}

et al. $(1988,2006)$ and Vennerstrøm (1991). The standard PC indices, PCN (North) and PCS (South), are based on 1 min samples of geomagnetic data from Qaanaaq and Vostok, respectively. The data are processed to reflect the transpolar convection that may carry plasma and magnetic fields from the front of the magnetosphere to the tail region building up excess energy that subsequently could be released in magnetic storm and substorm activity, which in turn could endanger power grids and other vital community systems.

The PC indices have proven useful for a range of space weather-related investigations and analyses of solar windmagnetosphere interactions. Thus, the PC indices have been used to monitor interplanetary geoeffective electric fields and solar wind pressure pulses, to analyze cross PC voltages, PC diameter, and general PC dynamics. Furthermore, the PC indices have been used to monitor auroral electrojet intensities, ionospheric Joule heating, global auroral power, and to predict ring current intensities (cf. Stauning, 2012; Troshichev and Janzhura, 2012, and references therein).

Power grids near the auroral zone are vulnerable to geomagnetically induced currents caused by variations in the magnetic field, in particular, the large and rapid variations associated with the explosive phase of strong substorms. 
Usually, such strong substorms require a build-up phase where the transpolar magnetospheric convection carries plasma and magnetic fields from the dayside to be accumulated in the tail region and provide the fuel for the explosive substorm developments. Former studies (e.g., Stauning, 2013b) have shown the close association between reported power grid disturbances associated with violent substorms and sustained high PC index levels, which makes the indices potentially useful for forecast services.

Concerning possible locations for index data collection, Papitashvili and Rasmussen (1999) examined PCN indices derived from geomagnetic recordings obtained from a range of observatories in Greenland in order to determine the effective area for collection of data to provide a useful PC index. They concluded that acceptable PC index values could be produced from data recorded within an area of $7.5^{\circ}$ in radius centred at the geomagnetic pole. In a more extended analysis still based on Greenland data, Papitashvili et al. (2001) concluded that the $\mathrm{PC}$ radius for effective $\mathrm{PCN}$ index derivation was $10^{\circ}$ in magnetic co-latitude.

The present work extends the analyses of possible index data sources to further observatories in the northern and southern PCs within the above latitude ranges. Section 2 provides a brief summary of PC index basics in order to define index derivation terms, relevant magnitude ranges, and major index series. In Section 3, quality assessment procedures are developed and used on existing PC index series to establish quality criteria. Data from selected geomagnetic observatories in Canada and Antarctica could be used, as will be shown in Sections 4 and 5, respectively, to provide alternative PCN and PCS index values of adequate quality. Examples of their usefulness are presented. Section 6 discusses methods and results, followed by a summary Section 7, and final conclusions.

\section{PC index basics}

It is complicated to scale solar wind intensities and related geospace effects directly from the magnetic data usually provided as components of the disturbed fields in a coordinate system fixed to the rotating Earth. Furthermore, the magnetic response on ground depends strongly on polar ionospheric Eregion electron densities which, in turn, have large daily and seasonal variations. These issues are handled in the PC index construction.

\subsection{PC index derivation}

The steps involved in the processing of data to derive useful PC indices are described, among other, in Troshichev et al. (2006). In order to handle the varying impact on the individual components, the magnetic variations in local coordinates are projected to an "optimum" direction in space, considered to be transverse to the dominant antisunward "forward" transpolar convection direction. Furthermore, the projected magnetic variations are scaled to let the index values equal (on the average) the related solar wind electric fields thereby removing dependencies on local time, season, and observatory location in order to derive consistent PC index values.
The optimum direction in space is given by its angle, $\phi$, to the east-west meridian. This angle and the average delay, $\tau$, between the solar wind impinging at the front of the magnetosphere and related effects on the PC magnetic fields, are found by maximizing the correlation between solar wind electric field data and projected polar magnetic variations. For an observatory at longitude $\lambda$, and for magnetic components provided in a geographical coordinate system, the projection angle, $V_{P R O J}$, could be expressed as a function of UThr (UT time in hours) through:

$$
V_{P R O J}=\lambda+U T h r \cdot 15^{\circ}+\phi .
$$

From the horizontal geomagnetic disturbance components, $(\Delta X, \Delta Y)$, derived as the deviations of the observed values $\left(X_{O B S}, Y_{O B S}\right)$ from the quiet level $\left(X_{Q L}, Y_{Q L}\right)$, the projected magnetic value $\left(\Delta F_{P R O J}\right)$ is defined by:

$$
\Delta F_{P R O J}=\Delta X \cdot \sin \left(V_{P R O J}\right) \pm \Delta Y \cdot \cos \left(V_{P R O J}\right),
$$

using + for the southern PC (e.g., Vostok) and - for the northern PC (e.g., Qaanaaq).

The solar wind geoeffective (or "merging") electric field (Kan and Lee, 1979) is derived by:

$$
E_{M}=V_{S W} \cdot B_{T} \cdot \sin ^{2}(\theta / 2)
$$

where $V_{S W}$ is the solar wind velocity, $B_{T}$ the transverse component $\left(B_{T}=\sqrt{\left(B_{Y}^{2}+B_{Z}^{2}\right)}\right.$ of the interplanetary magnetic field (IMF), while $\theta$ is the polar angle between the $Z$-axis of the geocentric solar-magnetospheric coordinate system and the transverse IMF component. The projected polar magnetic variations [in $\mathrm{nT}$ ] are assumed to be linearly related to the (delayed) merging electric field [in $\mathrm{mV} / \mathrm{m}$ ] through the relation:

$$
\Delta F_{P R O J}=\alpha E_{M}+\beta,
$$

where the coefficients $\alpha[\mathrm{nT} /(\mathrm{mV} / \mathrm{m})]$ and $\beta[\mathrm{nT}]$ are found by least squares regression on basis of a large ensemble (e.g., a complete solar cycle) of solar wind electric field data and related ground magnetic variations. For each observatory, the derived calibration parameters, $(\alpha, \beta, \phi)$ are tabulated to define their variations with time-of-day and season. They are invariant over years.

The PC index $[\mathrm{mV} / \mathrm{m}]$ is now defined by the inverse relation:

$$
\mathrm{PC}=\left(\Delta F_{P R O J}-\beta\right) / \alpha,
$$

which provides index values scaled to equal $E_{M}$ (on the average) and thus (in principle) independent of local properties such as local time of day, season, and location within either PC.

\subsection{PC index interpretation}

Negative PC index values indicate reverse convection conditions, which typically occur when the IMF has a dominant strong northward (positive) component (NBZ). In such cases the usual two-cell (DP2) forward polar convection patterns are weakened, while inner two-cell (DP3) reverse convection patterns 
Table 1. Main characteristics of scaling conditions for frequently used PC index versions.

\begin{tabular}{lllll}
\hline Version & Epoch for scaling & Solar activity & Reverse convection & Reference level \\
\hline OMNI & $1977-1980$ & Peak of cycle & Frequent & No $Q D C, B L$ only \\
AARI & $1998-2001$ & Peak of cycle & Frequent & $B L$ and $Q D C^{*}$ \\
IAGA & $1997-2009$ & Cycle average & Average & $B L$ and $Q D C^{* *}$ \\
DMI & $1997-2009$ & Cycle average & Excluded & $B L$ and $Q D C^{* * *}$ \\
\hline
\end{tabular}

\footnotetext{
${ }^{*} Q D C$ : Based on running 30 days quiet samples (Janzhura and Troshichev, 2008).

${ }^{* *}$ QDC: Running 30 days quiet samples + solar wind sector contribution (Janzhura and Troshichev, 2011).

${ }^{* * *} Q D C$ : 40 days solar rotation weighted quiet samples (Stauning, 2011).
}

may emerge (e.g., Huang et al., 2000). During NBZ conditions the transfer of power from the solar wind to the magnetosphere is low and the global magnetic activity level is weak.

With forward convection (positive PC index values) the overall magnetic activity expressed, for instance, through auroral electrojet indices AE (e.g., Troshichev et al., 2012; Stauning, 2012), the midlatitude Kp indices (Stauning, 2012), and the ring current Dst indices (Stauning et al., 2008; Troshichev et al., 2011) generally increases with increasing PC index level. The development of global magnetic disturbances relates to the convection properties in both $\mathrm{PCs}$ and is more closely related to the non-negative, dual $\mathrm{PC}$ index formed from a qualified average of PCN and PCS than to either of the single PC PCN or PCS indices (Stauning, 2007).

In an investigation of substorms occurring from 1997 to 2004 during steady solar wind conditions, the average PC level at onset was found to be $3 \mathrm{mV} / \mathrm{m}$ (Stauning, 2012). For the more general cases, substorm onsets would occur at PC index levels of $1.5 \pm 0.5 \mathrm{mV} / \mathrm{m}$ according to Troshichev et al. (2014), while the growth phase could vary from $60 \mathrm{~min}$ decreasing to near zero with increasing PC index levels (Janzhura et al., 2007).

For PC index levels above the onset threshold the strength and frequency of magnetic storms and substorms generally increase with increasing index magnitude. The developments of repeating strong substorm conditions (sawtooth events) are associated with persistent high PC index levels generally above $6 \mathrm{mV} / \mathrm{m}$ (Troshichev and Janzhura, 2009).

In a study of the effects of strong substorms (Stauning, 2013 b), observed geomagnetic variations and related high voltage (HV) power-grid disturbances in Sweden were examined for 11 cases. The reported HV line disruption events were preceded by PCN index values exceeding $10 \mathrm{mV} /$ $\mathrm{m}$ ("alert" level) through one or more hours before the stroke. For the stronger cases in 1982, 1989 and 2003, the PCN index value averaged through the hour preceding the disturbances exceeded $15 \mathrm{mV} / \mathrm{m}$ which could be termed "red alert" level.

The association of PC index values with further wellestablished activity indices and the specification of relations between index levels and developments of magnetic storms and substorms may help to define the range of index values, generally above $2-5 \mathrm{mV} / \mathrm{m}$, of interest for space weather applications and to assess demands to index quality at such index levels.

\subsection{PC index versions}

In order to provide a reference scale for judging the quality of PC index values derived on basis of data from new locations, quality analyses shall be conducted for a range of widely used PC index series. PCN and PCS indices made available at http:// pcindex.org are generated according to the procedure endorsed by the International Association for Geomagnetism and Aeronomy (IAGA) in 2013 and here termed "IAGA" versions. A general description of this index version has been provided by Troshichev (2011) and made available at http://geophys. aari.ru/Description.pdf, with details described in the referenced publications and in the software listings.

Further widely used index versions are discussed in Stauning (2013c) comprising, among other, the "OMNI" version developed by Vennerstrøm (1991) with index values made available by the OMNIweb data service, and the "AARI" version developed at the Arctic and Antarctic Research Institute (Troshichev et al., 2006). For the index version that in the following will be termed "DMI" version, a description of the steps in the processing as well as tables of monthly average hourly parameters for PCN (Qaanaaq) and PCS (Vostok) are available on-line in Stauning (2016).

The main differences between the versions resides in the solar activity level in effect during the epoch used for deriving scaling parameters, in the handling of reverse convection samples in the scaling, and in the definition of the quiet reference level with or without including the quiet daily variation $(Q D C)$ on top of the base level $(B L)$. A summary of characteristics is provided in Table 1.

\section{PC index quality}

The basic quality control comprises the verification demands listed in the description "PC indices" by Troshichev (2011) made available at http://pcindex.org:

- PCN and PCS indices should be consistent with the interplanetary electric field, $E_{M}$;

- PCN and PCS indices should be in close agreements with each other irrespective of season and UT time;

- Indices should not demonstrate seasonal variation;

- Indices should not demonstrate regular daily variation (i.e. dependence on UT-time).

In consequence of the construction of the PC indices (cf. Eqs. (1)-(5)) and to agree with these demands, the ratio between PC index values and values of the interplanetary electric field, $E_{M}$, should be invariant to season, time of day, and $\mathrm{PC}$. The challenge is now to derive a representation for the actual distributions of the ratio $\mathrm{PC}$ index/ $E_{M}$ at the different conditions. 


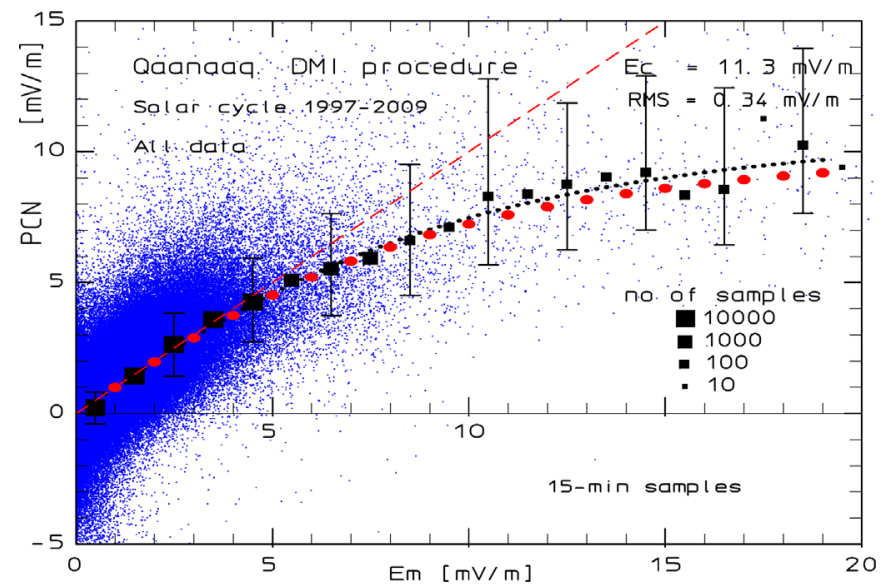

Fig. 1. Display of PCN vs. $E_{M}$ for the solar cycle epoch 1997-2009. Dashed line indicates equality. Square dots mark bin averages, error bars indicate standard deviation within every other bin. The curve of large red dots shows common reference (Eq. (6) with $\mathrm{E}_{\mathrm{C}}=10.5 \mathrm{mV} /$ $\mathrm{m})$, while the curve of smaller dots indicates best fit between the function in Eq. (6) (with variable $E_{C}$ ) and the bin average PCN values. The parameters from the fit, $E_{C}$ and the minimum weighted RMS deviation are noted in the plots.

Figure 1 presents the relations between PCN index values and corresponding values of $E_{M}$, delayed by $\tau=20 \mathrm{~min}$ (Stauning, 2016) to compensate for the propagation of effects from the bow shock nose (BSN) to the PC. The $E_{M}$ values have been derived from OMNI combined interplanetary satellite BSN-adjusted solar wind magnetic field and velocity data (http://omniweb.gsfc.nasa.gov). The straight dashed line indicates equality between $E_{M}$ and PCN. The small (blue) dots are the individual samples provided as $15 \mathrm{~min}$ averages in order to enable a detailed visual impression of the data. The square dots in Figure 1 indicate averages of PCN values through each unit of $E_{M}$. The size of the dots specifies the number of involved samples $(\mathrm{N})$ on the scale displayed in the diagram, while the error bars indicate bin-interval standard deviations displayed every other bin.

It is seen from Figure 1 that the average values of PCN track the corresponding $E_{M}$ values quite well (within $0.2 \mathrm{mV} /$ $\mathrm{m})$ up to around $5 \mathrm{mV} / \mathrm{m}$. Above that level the PCN values appear to saturate much like the driving cross-PC electric field (e.g., Ridley, 2005). Thus, it is clear from Figure 1 that the linear relation (equality) between average index and merging electric field values assumed in equation (5) fails at the larger and more important index levels. A more complex relation is needed.

The curve of large red dots in Figure 1 and further similar diagrams indicates the functional relation:

$$
\mathrm{PC}=E_{M} / \sqrt{\left(1+\left(E_{M} / E_{C}\right)^{2}\right)}
$$

with $E_{C}$ fixed at $10.5 \mathrm{mV} / \mathrm{m}$. The relation was determined as the best fit between PC index and $E_{M}$ values for magnetic storm cases during 1995-2005 (Stauning, 2012) and is used here to provide a common reference (not a target) to ease visual comparisons of various displays of PC index values versus $E_{M}$. It is clear that the shape of this curve provides a good representation of the linear relation at small $E_{M}$ values and shows PC index saturation effects at larger $E_{M}$ levels. The precise course could be adjusted simply by changing the parameter $E_{C}$ in equation (6).

The curve depicted by the small black dots in Figure 1 indicates the weighted least squares fit to the bin-average values using the reference formula in equation (6) with a variable parameter, $E_{C}$. The squared deviations are weighted with the logarithm $\left(\log _{10}(\mathrm{~N})\right)$ of the number of samples $(\mathrm{N})$ in the bins, and not $\mathrm{N}$, in order to avoid results dominated by the overwhelming number of small PCN and $E_{M}$ values (e.g., less than $5 \mathrm{mV} / \mathrm{m}$ ), which for space weather purposes are less important. Averages representing less than 3 samples are neglected in the fitting. The parameters resulting from the fit, $E_{C}$ and the minimum weighted RMS deviation, are noted in the plots.It is seen from Figure 1 that the fitted curve of small dots (here with $E_{C}=11.3 \mathrm{mV} / \mathrm{m}$ ) represents the bin-average index values (square dots) quite well with a small weighted RMS deviation (here $0.34 \mathrm{mV} / \mathrm{m}$ ) compared, for instance, to index values above $5 \mathrm{mV} / \mathrm{m}$. Thus, the $E_{C}$ value may conveniently represent the distribution of bin-average PCN values vs. $E_{M}$. With large values of the $E_{C}$ parameter, the distribution function approaches the ideal linear form, $P C=E_{M}$ (assumed when deriving calibration parameters), while for small values of $E_{C}$ the distribution would show saturation at low values of the merging electric field, $E_{M}$. According to equation (6), average PC index values are half the corresponding $E_{M}$ values at $E_{M}=\sqrt{3} \cdot E_{C}$ (quantification of saturation effect).

Since the PC indices according to equations $1-5$ are scaled to $E_{M}$, a solar wind parameter (Troshichev et al., 2006), then the relation between average PC index and $E_{M}$ values should (in principle) remain the same (same $E_{C}$ ) through all hours of the day, seasons of the year, and locations within either PC (Troshichev, 2011; Troshichev and Janzhura, 2012). Thus, displays of the type shown in Figure 1 enable assessments of index quality. The primary index quality parameter is the spread in $E_{C}$ (which should be small) between values found for ensembles of PC index values grouped at different times of the day and for different seasons. A secondary quality parameter is the magnitude of the $E_{C}$ fit parameter (which should be large) as it indicates possible saturation effects. The RMS figures noted in Figure 1 and corresponding plots are used along with a visual inspection to ensure proper fitting.

In order to derive a "quality scale", quality parameters have been derived from existing series of PCN indices in different versions comprising OMNI PCN values, AARI PCN values, the IAGA-endorsed PCN values, and DMI PCN values. An interval spanning an entire solar cycle has been divided in segments for summer (May-Aug), equinox (Mar-Apr \& SepOct), and winter (Nov-Feb) months. Each segment has then been subdivided into daytime (12-20 UT) and night time (00-08 UT) values noting that local solar and magnetic noon at Qaanaaq is at about 16 UT.

For each of the PCN versions considered, and for each of the seasonally and local time delimited data sets, plots of the type shown in Figure 1 have been made in addition to plots for the entire interval. Figure 2 presents for each PCN version a composite of plots for each pair of winter night and summer daytime values considered to represent extreme cases. These plots display averages marked by the square dots and error bars only; individual samples are not shown here. 
a.

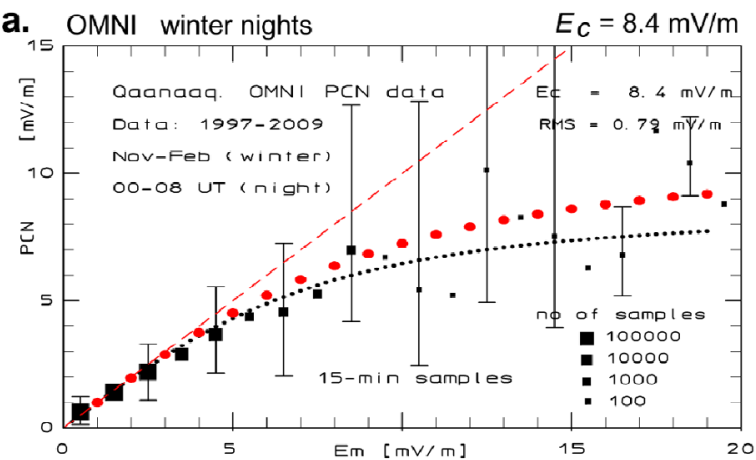

c.

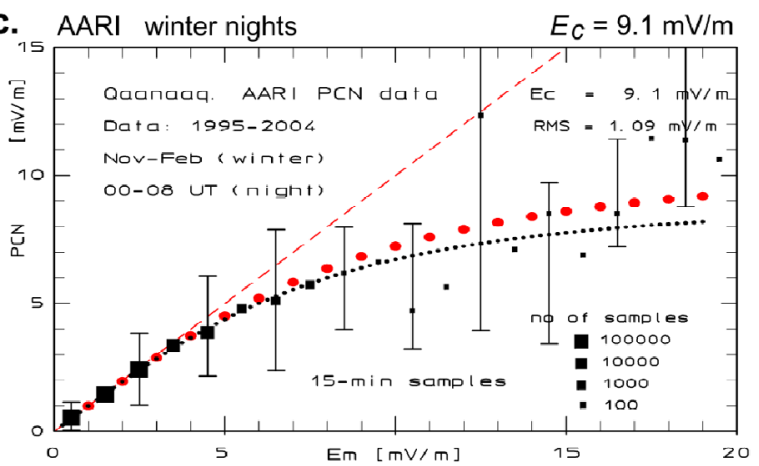

e. IAGA winter nights $E_{C}=11.1 \mathrm{mV} / \mathrm{m}$

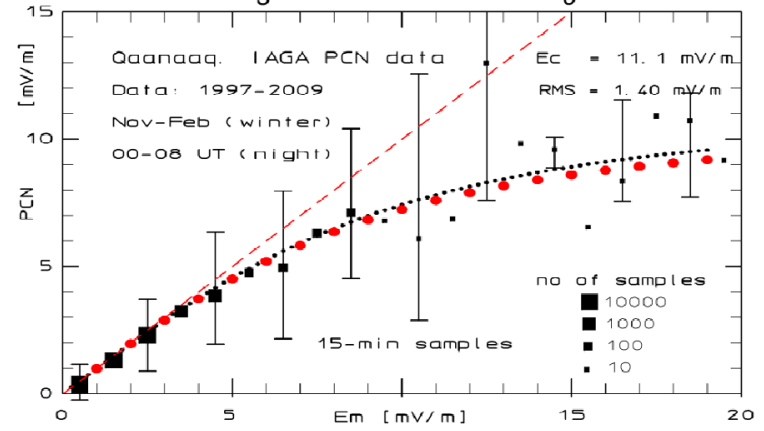

g. DMl winter nights $\quad E_{C}=11.4 \mathrm{mV} / \mathrm{m}$

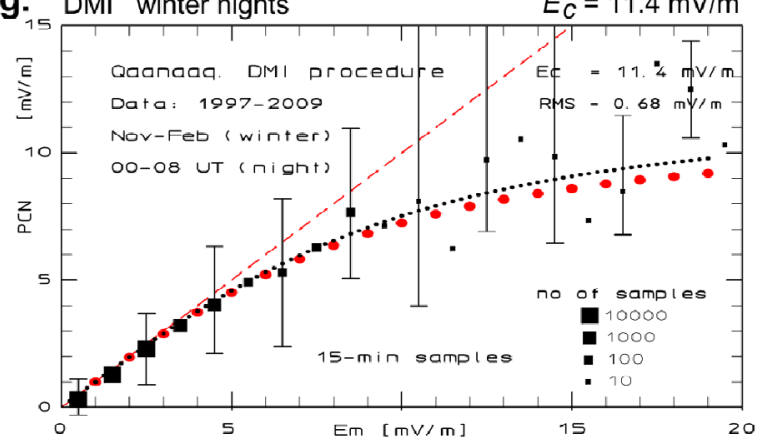

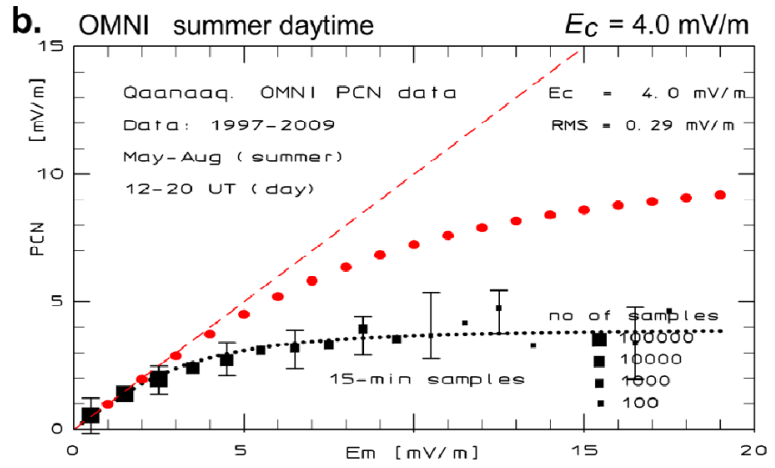

d. AARI summer daytime $\quad E_{C}=5.6 \mathrm{mV} / \mathrm{m}$

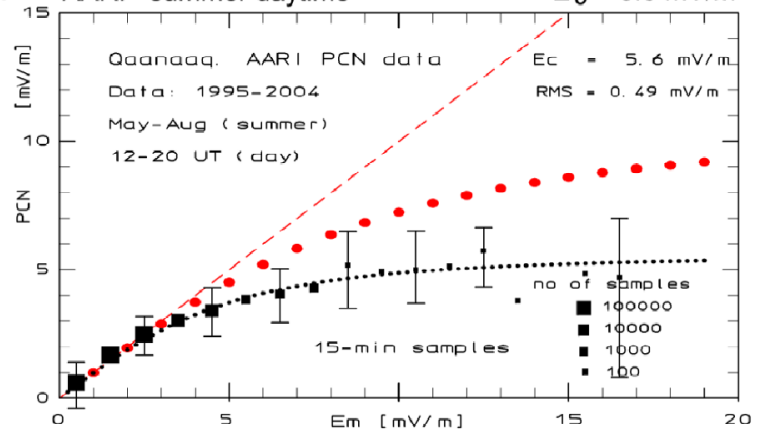

f. IAGA summer daytime $E_{C}=7.2 \mathrm{mV} / \mathrm{m}$

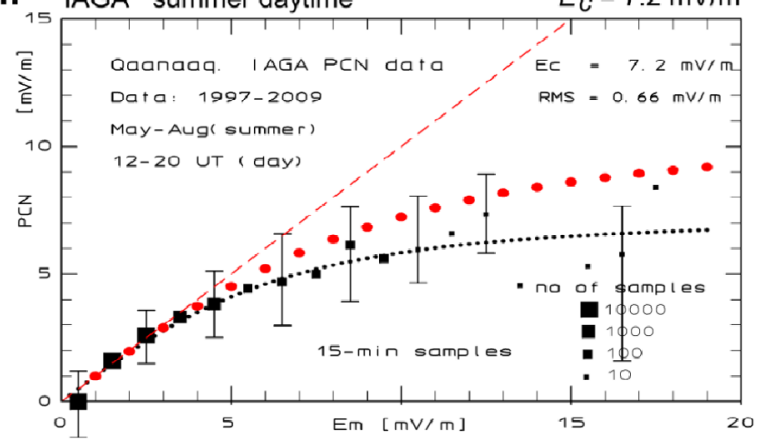

h. DMl summer daytime $\quad E_{C}=9.7 \mathrm{mV} / \mathrm{m}$

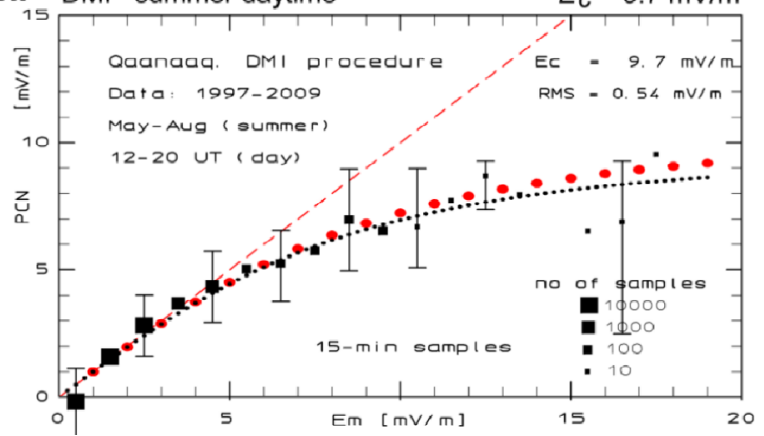

Fig. 2. Index quality plots of PCN vs. $E_{M}$ in the format and notation of Figure 1 for winter nights and summer daytime cases for OMNI (a + b), AARI $(c+d)$, IAGA $(e+f)$, and DMI $(g+h)$ index versions.

The dashed line of equality and the reference curve (Eq. (6) with $E_{C}=10.5 \mathrm{mV} / \mathrm{m}$ ) marked by the large dots are included in the diagrams of Figure 2. The curves indicated by the small dots display the least squares weighted fit of the form of equation (6) with a variable $E_{C}$. The PC index source, the season displayed, and the value of $E_{C}$ from the fit are noted on top of the individual diagrams and displayed in Table 2.
The values found from these data sets are summarized in Table 2. Note that the acronym for Qaanaaq is THL. The table indicates the epoch of data used for the derivation of the quoted $E_{C}$ quality figures. The $E_{C}$ (all) values were found from "alldata" plots like Figure 1, while the winter nights, $E_{C}(\mathrm{wn})$, and summer daytime, $E_{C}(\mathrm{sd})$, values are seen in Figure 2. The spreads in $E_{C}$ between winter nights and summer days, 
Table 2. Quality parameters for different PCN index versions (and Dome-C PCS).

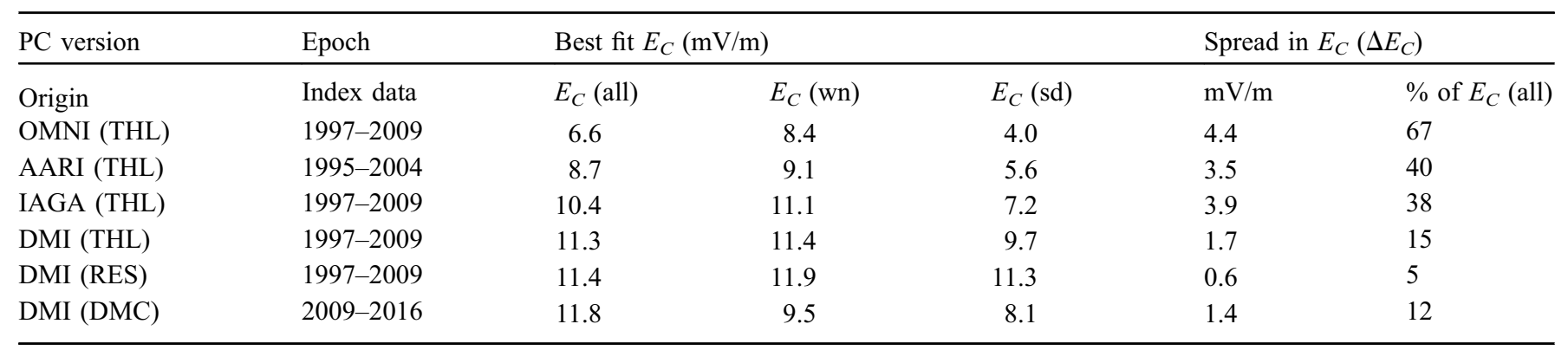

Table 3. Geographic and geomagnetic parameters at $100 \mathrm{~km}$ of altitude for selected stations.

\begin{tabular}{llllcrrr}
\hline Observatory & Station & Latitude & Longitude & CGMlat & CGMlon & LT=00 & MLT $=00$ \\
\hline Name & Acr. & Deg. & Deg. & Deg. & Deg. & UThrs \\
Qaanaaq & THL & 77.48 & 290.83 & 85.29 & 31.30 & 4.61 \\
Alert & ALE & 82.50 & 297.65 & 87.10 & 99.74 & 4.16 \\
Eureka & EUR & 80.00 & 274.10 & 88.42 & 327.09 & 21.74 & 5.73 \\
Resolute bay & RES & 74.68 & 265.10 & 83.27 & 319.40 & 6.33 \\
Dome-C & DMC & -75.25 & 124.17 & -88.81 & 43.07 & 15.72 \\
Vostok & VOS & -78.46 & 106.84 & -83.57 & 54.80 & 16.88 \\
\hline
\end{tabular}

$\Delta E_{C}=E_{C}(\mathrm{wn})-E_{C}(\mathrm{sd}) \mathrm{in} \mathrm{mV} / \mathrm{m}$ or in percents relative to $E_{C}$ (all), are listed in Table 2 for the different versions. The DMI Resolute (RES) PCN values and the DMI Dome-C (DMC) PCS cases shown in the bottom two rows are presented in Sections 4 and 5, respectively, and included here for easy reference.

The distributions of PCN vs. $E_{M}$ in Figure 2 indicate that the winter night data, generally, present higher values of the $E_{C}$ parameter than the averages, while the summer daytime data sets display lower values. The reported values are referenced to in Sections 4 and 5 and further discussed in Section 6.

\section{PC indices derived from further geomagnetic observatories}

The observing sites considered here comprise stations in Greenland, Canada, and Antarctica listed with their geographic and geomagnetic coordinates in Table 3. They are all located within the co-latitude range $\left(7.5^{\circ} \mathrm{CGM}\right)$ specified in Papitashvili and Rasmussen (1999). The table also presents the UT times for local solar and magnetic midnight. The corrected geomagnetic (CGM) parameters have been derived for $100 \mathrm{~km}$ of altitude using the NASA Vitmo utility made available at: http://omniweb.gsfc.nasa.gov/vitmo/cgm_vitmo. html

In order to derive $\mathrm{PC}$ indices from magnetic data recorded at a location differing from the position of the standard observatories, methods to derive the quiet reference values must be developed. Projection angles must adopt the new longitude, and new sets of the daily and seasonally varying calibration parameters $(\alpha, \beta, \phi)$ must be calculated (cf. Eqs. (1)-(5)).
For each of the listed observatories, the available data from an epoch of years spanning, if possible, the complete solar cycle throughout the years 1997-2009 have been used for the calculation of PC index calibration parameters. For some of the observatories, a limited availability of data has forced the use of different reference epochs spanning still, however, solar maximum as well as solar minimum years. PC index values have then been derived for all years with available observatory data. The "DMI" methods described in Stauning (2016) have been used to calculate PC index values for the new locations. Quality parameters for these index values have been derived using the method defined in Section 3 to be compared with corresponding quality parameters for the other PC index series mentioned in Table 1 (cf. discussions in Sect. 6).

\subsection{Resolute Bay observatory as an alternative PCN index source}

The geomagnetic observatories in Canada listed in Table 3 could be candidates for alternative sources of PCN index values, for instance, for space weather services. Eureka (EUR) magnetic observatory has a very favourable position being close to the CGM pole. However, the data collection is rather uncertain and the available data appear erratic. The Alert observatory is also in a favourable position close to the geomagnetic pole. Reliable data have been obtained for some years (1996-2005) enabling calculation of PC index calibration parameters. However, the quality of recordings through recent years is not up to observatory standards.

The observatory at Resolute Bay (RES) at $83.27^{\circ} \mathrm{CGM}$ latitude could be candidate for an alternative PCN index source. The station has supplied observatory quality data from 

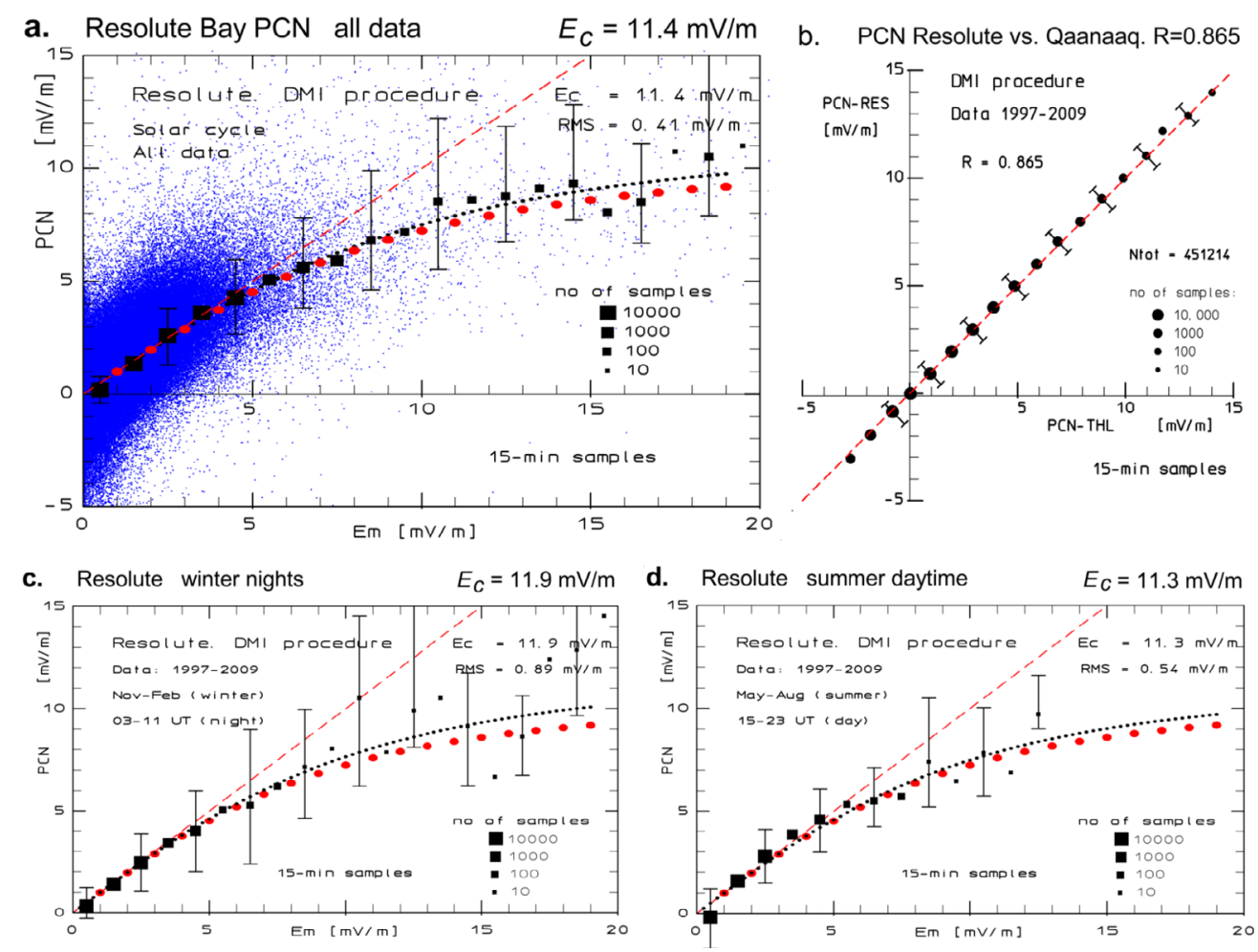

Fig. 3. (Panel a) Resolute PCN in the DMI version vs. $E_{M}$ for the solar cycle epoch 1997-2009 in the format and notation of Figure 1. (b) Bin average Resolute PCN vs. Qaanaaq PCN. The dashed red line indicates equality. (c) Resolute PCN vs. $E_{M}$ for winter nights and (d) Resolute PCN vs. $E_{M}$ for summer daytime cases in the format and notation of Fig. $2 \mathrm{a}-\mathrm{h}$.

(at least) 1988 up to present and made them available trough INTERMAGNET (http://intermagnet.org) and the World Data Centers. The station is located $2^{\circ}$ in CGM latitude equatorward of Qaanaaq. In order to investigate this option, the quality assessment methods outlined above have been applied to PCN index values obtained from Resolute data.

Figure 3a presents the PCN- $E_{M}$ relations for 1997-2009 in the format of Figure 1, while Figures $3 c$,d present the winter nights and summer daytime cases in the format of Figure $2 \mathrm{a}-\mathrm{h}$. The quality parameters $\left(E_{C}\right)$ noted in the diagrams are added to Table 2. The correlation between $15 \mathrm{~min}$ PCN values derived from Resolute and Qaanaaq data, respectively, is shown in Figure $3 \mathrm{~b}$. The figure display average values within each unit of the indices. The dashed red line indicates equality. The number of samples in each bin is indicated by the size of the dot and the RMS standard deviations are indicated by the error bars. The correlation value $(R=0.865)$ noted in Figure $3 \mathrm{~b}$ is displayed in Table 4.

Comparing Figures 3a,c,d, to Figures 1 and 2 indicates that the over-all quality of the PCN values derived from Resolute data is comparable to that of the index values derived from Qaanaaq data. The all-data $E_{C}$ parameter for Resolute is close to the value for DMI-THL (11.4 vs. $11.3 \mathrm{mV} / \mathrm{m})$. The winter night and summer days selections presented in Figure $3 \mathrm{c}$, d display a spread in the $E_{C}$ parameter of $0.6 \mathrm{mV} / \mathrm{m}$ or $5 \%$, which is actually better than the $\Delta E_{C}$ values for the other PCN versions of Table 2. Thus, PCN index values derived from Resolute Bay magnetometer data could be considered to be as qualified as the PCN index values based on Qaanaaq data.
A further quality parameter for PC indices is their independence of observatory location. This feature is further documented by the close correlation between PCN indices derived from Resolute data versus those derived from Qaanaaq data displayed in Figure 3b. The correlation coefficient for the 1997-2009 epoch is 0.865 based on 15 min samples. The correlation between the two PCN data sets is limited by the occurrence of reverse convection that gives negative index values. Reverse convection events occurring during NBZ conditions are mostly observed in a narrow local time sector close to local solar and geomagnetic noon (e.g., Stauning et al., 2002), which for the two stations occur at different UT times. Hence, there is an abundance of anti-correlated samples, where the index values have opposite signs. For the cases with positive index values, differences between averages are less the $0.5 \mathrm{mV} / \mathrm{m}$, while RMS standard deviations between the two $\mathrm{PCN}$ versions are $0.5-1.0 \mathrm{mV} / \mathrm{m}$ for the bins up to $15 \mathrm{mV} / \mathrm{m}$.

\subsection{Example case of application of PCN indices based on Resolute magnetic data}

As an example case, PCN data from the magnetic storm on 13 March 1989 are presented in Figure 4. For this day, there are no data for the solar wind electric field, $E_{M}$, in the OMNI data base, but Qaanaaq as well as Resolute magnetic data are available to derive the PCN index values presented in the figure. The "alert" and "red alert" levels suggested in Stauning (2013b) are indicated by the horizontal dotted and dashed red lines. 
Table 4. Results from correlation analyses.

\begin{tabular}{llll}
\hline Data sets & Fig. & Epoch & Corr. $(R)$ \\
\hline IAGA PCS vs. PCN & $6 \mathrm{a}$ & $2009-2016$ & 0.762 \\
DMI PCS vs. PCN & $6 \mathrm{~b}$ & $2009-2016$ & 0.790 \\
PCS-DMC vs. PCN-THL & $6 \mathrm{c}$ & $2009-2016$ & 0.841 \\
PCS-DMC vs. PCN-RES & $6 \mathrm{~d}$ & $2009-2016$ & 0.800 \\
PCS-DMC vs. PCS-VOS & $5 \mathrm{~b}$ & $2009-2016$ & 0.947 \\
PCN-RES vs. PCN-THL & nc & $2009-2016$ & 0.841 \\
PCN-RES vs. PCN-THL & $3 \mathrm{~b}$ & $1997-2009$ & 0.865 \\
\hline
\end{tabular}

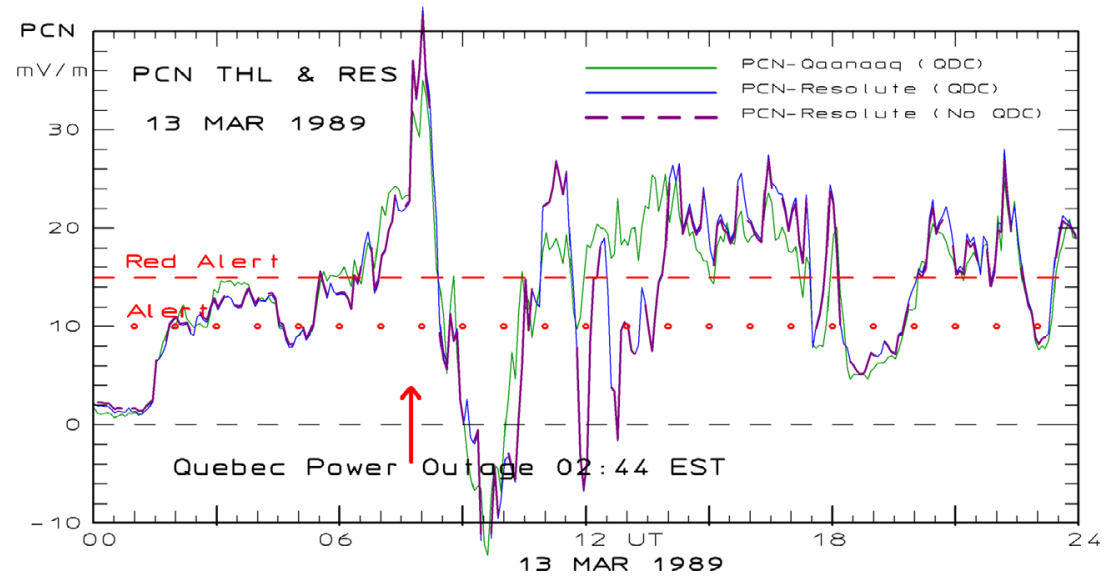

Fig. 4. PCN index values for 13 March 1989 derived from Qaanaaq data (green line) and from Resolute data with $Q D C$ (blue line) and without $Q D C$ (magenta line). Solar wind electric field data were not available at this event. "Alert" and "Red Alert" levels are indicated by the dotted and dashed red lines.

In Figure 4, the green line presents PCN index values derived from Qaanaaq magnetic data by the "DMI" method using a quiet level $(Q L=B L+Q D C)$ comprising base level value $(B L)$, interpolated from yearly values, and $Q D C$ derived by using the "Solar Rotation Weighted" (SRW) method. The calibration parameters $(\alpha, \beta, \phi)$ are provided in Stauning (2016). The blue line presents PCN values derived from Resolute magnetic data using $Q L=B L+Q D C$, while the magenta dashed line presents PCN values derived from Resolute data using $B L$ only and a "no$Q D C$ " set of calibration parameters.

The time of the comprehensive power outage in Quebec at 02:44 EST (=07:44 UT) is marked by an arrow. The event was preceded by $6 \mathrm{~h}$ of "alert" (PCN $>10 \mathrm{mV} / \mathrm{m})$ conditions with $2 \mathrm{~h}$ of "red alert" (PCN $>15 \mathrm{mV} / \mathrm{m})$ conditions immediately preceding the outage. It might be noted, that there is a general close agreement between Qaanaaq and Resolute PCN values except for a few intervals at around $12 \mathrm{UT}$ in the wake of the violent substorm. The close agreement between the " $Q D C$ " and the much simpler "no $Q D C$ " cases should also be noted. Their traces are almost indistinguishable. PCN index values based on Resolute data and using either the "with-QDC" calibration parameters, if $Q D C$ s are continually derived, or the "no- $Q D C$ " (" $B L$ only") parameters, could be a worthwhile asset for verification or back-up of the standard PC indices and a supplement to satellite-based solar wind data for space weather forecast services. Any small local computer could easily convert current magnetometer readings into useable PC index values.

\section{Dome-C observatory as an alternative source for the PCS index}

Apart from the Vostok observatory managed by the Russian Arctic and Antarctic Research Institute in St. Petersburg (http:// geophys.aari.nw.ru) there are few observatories within the central southern PC to provide continuous recordings of the geomagnetic field through recent years. One is the Dome-C, Concordia observatory managed by a European consortium. The station has a very attractive position for deriving a PCS index since it is situated almost directly at the geomagnetic pole (CGM latitude $=-88.81^{\circ}$ ). The magnetic data from the observatory are made available through the INTERMAGNET portal (http:// intermagnet.org) and range from 2009 to present. The quality of the data appears good with stable baselines for the components (Chambodut et al., 2009; Di Mauro et al., 2014).

\subsection{Quality control of PCS indices derived from Dome-C data}

Following the procedures detailed in Stauning (2016) for determination of the quiet level $(Q L=B L+Q D C)$ and 

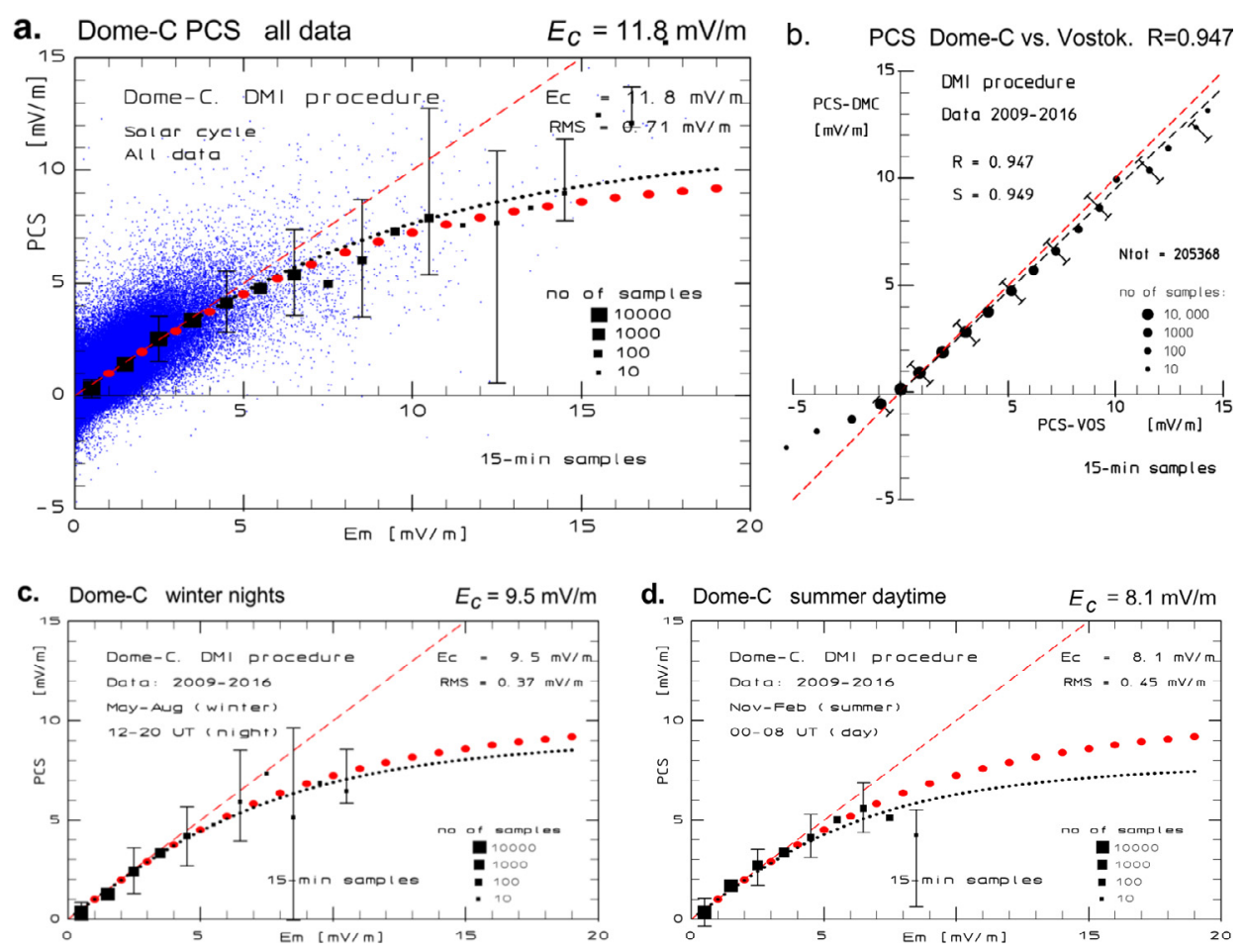

Fig. 5. Display in the format and notation of Figure 3 of PCS- $E_{M}$ relations for (a) all data, (c) winter nights, and (d) summer daytime. Correlation between PCS(Dome-C) and PCS(Vostok) in panel b. The read dashed line indicates equality. The black line (slope $S=0.949$ ) represents the best fit between positive values of the two PCS data sets.

calculation of the calibration parameters $(\alpha, \beta, \phi)$, PCS index values have been derived on basis of magnetic observations from DMC through the interval of available data. The quality control steps, deriving $E_{C}$ values and inter-station correlations, described above have been applied to the derived PCS index values and are presented in Figure 5. The red dashed line in Figure $5 \mathrm{~b}$ represents equality between the two sets of index values. The black dashed line with slope $S=0.949$ (noted in the diagram) extending from the origin in Figure $5 \mathrm{~b}$ represents the linear fit between the positive index values and has been included to indicate that Vostok indices are around 5\% larger than the Dome-C indices, a difference that is not disclosed by the calculation of the correlation coefficient.

The spread, $1.4 \mathrm{mV} / \mathrm{m}$ or $12 \%$ of $E_{C}$ (all), in the values of $E_{C}$ between 9.5 (wn) and 8.1 (sd) is comparable to corresponding values for PCN in the Qaanaaq DMI(THL) and Resolute DMI(RES) versions (Tab. 2). However, the fits are not well qualified due to the sparse amount of cases with large PC index values within the interval from 2009 to 2016 compared to the cases seen in the diagrams in Figures 2 and 3 for the epoch from 1997 to 2009. The corresponding data sets for PCN (Qaanaaq) and PCS (Vostok) for the epoch 20092016 (not shown) have the same conditions.

The PCS indices (DMI version) derived from Vostok data have been qualified on basis of data from epoch 1997-2009. With a correlation coefficient of 0.947 , the close correlation for epoch 2009-2016 between PCS(Dome-C) and PCS(Vostok) seen in Figure $5 \mathrm{~b}$ and reported in Table 4 substantiates the qualification of Dome-C data for PC index derivation. The further quality criterion mentioned in Section 2 stating that the PC indices should be consistent between the PCs would be fulfilled by a high correlation between PCS(Dome-C) and PCN (Qaanaaq). The interhemisperic match could not be perfect since in addition to the above-mentioned reverse convection problem, the index values depend to some degree on the sign of IMF $B_{Y}$, which does not enter the defining equation for $E_{M}$ (cf. Eq. (3)). The disturbing effects from IMF $B_{Y}$ are different in the opposite PCs (e.g., Troshichev et al., 2006), but could be minimized by appropriate handling of the $Q D C$ (Stauning, 2011).

Like the index quality criteria based on the $E_{C}$ parameter for the independence of time-of day and season, a quality scale for consistency between the PCs is established by examination of correlations for the epoch 2009-2016 within the existing PCN and PCS index series, the IAGA series (http://pcindex. org), and the DMI series (Stauning, 2016). These "scaling" correlations are presented in Figure 6a and b. Figure 6c then presents the correlation between PCS indices based on Dome$\mathrm{C}$ data and PCN indices based on Qaanaaq data, both derived by the DMI procedure (with $Q D C$ ), while Figure $6 \mathrm{~d}$ presents the correlation between Dome-C-based PCS and Resolutebased PCN indices. The correlation coefficients are summarized in Table 4. The values in the uppermost row are based on IAGA PCN and PCS data from http://pcindex.org while the remaining values are based on calculations using indices derived by the DMI methods (Stauning, 2016).

It should be noted from Figure $6 \mathrm{a}, \mathrm{b}$ that the positive PCS index values based on Vostok data are systematically a few percent larger than the PCN indices based on Qaanaaq data. The same tendency was seen in the correlation of PCS indices based on Dome-C data against the Vostok-based indices presented in Figure 5b. The reason for these small disparities is not known at present. 
a.

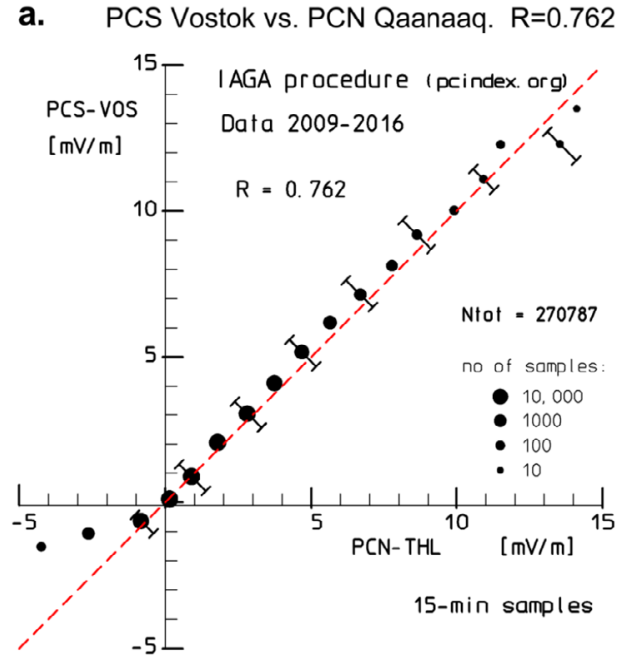

c. PCS Dome-C vs. PCN Qaanaaq. $\mathrm{R}=0.841$

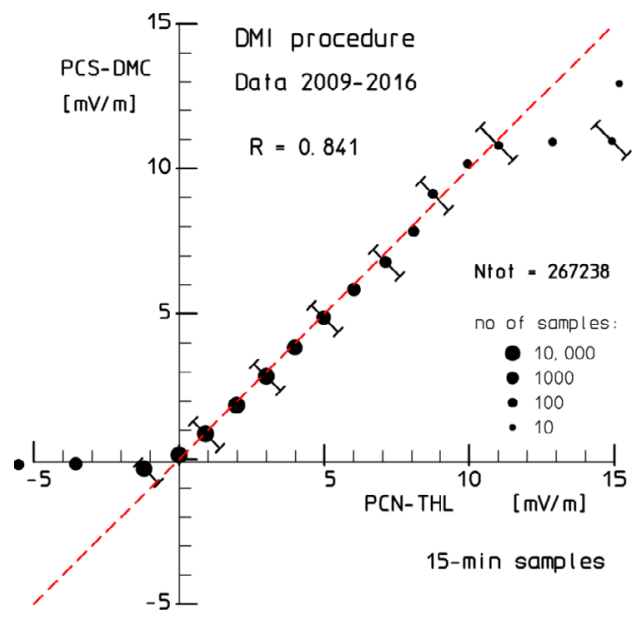

b. PCS Vostok vs. PCN Qaanaaq. R=0.790

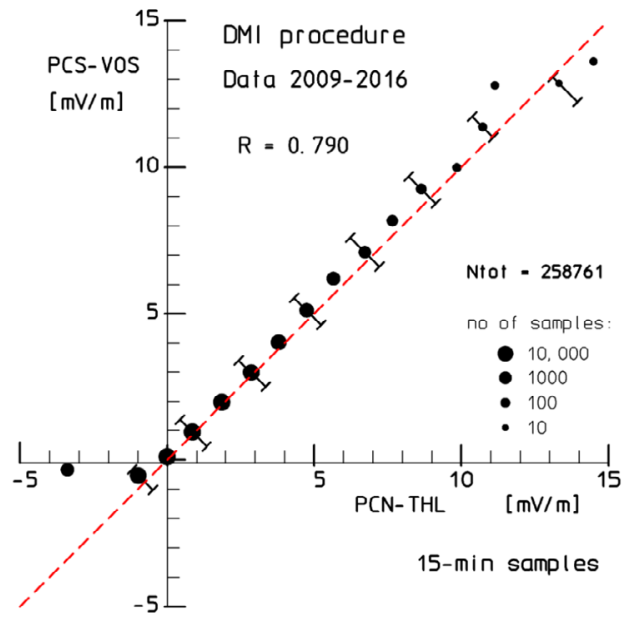

d. PCS Dome-C vs. PCN Resolute. $\mathrm{R}=0.800$

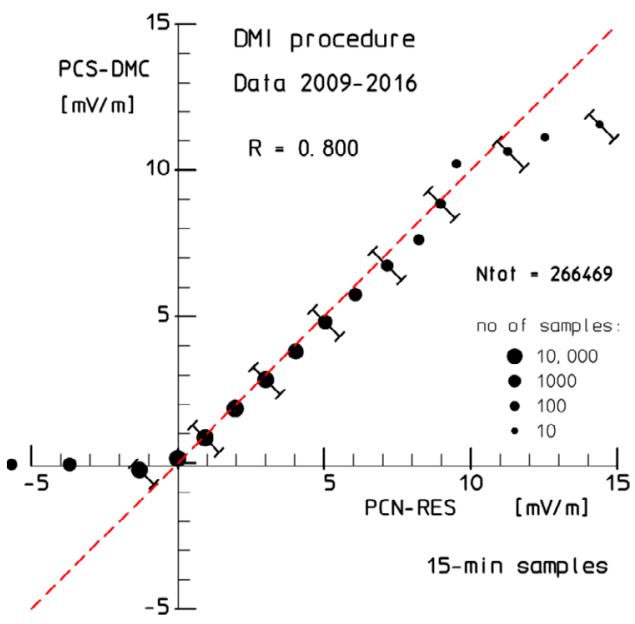

Fig. 6. Correlation in the format and notation of Figure $3 b$ between (a) IAGA PCN (THL) and PCS (VOS), (b) DMI PCN (THL) and PCS (VOS), (c) DMI PCN (THL) and PCS (DMC), and (d) DMI PCN (RES) and PCS (DMC).

The correlation coefficient for the IAGA PCS vs. PCN data is 0.762 (Fig. 6a, Tab. 4). It should be noted that the correlation coefficient for the IAGA indices would increase to $R=0.784$ if the epoch was changed to the interval 2008-2016 and year 2011 (with poor PCS data, cf. Sect. 5.2) omitted. The DMI Vostok-based PCS vs. the Qaanaaq-based PCN data set gives a correlation coefficient of $R=0.790$ (Fig. 6b). A shift to epoch 2008-2016 with omission of year 2011 changes the DMI PCS vs. PCN correlation coefficient with a minor amount to $R=0.791$, which indicates proper handling of the baseline and $Q D C$ through 2011 in the DMI version.

With a correlation coefficient of $R=0.841$ (Fig. 6c), the Dome-C-based PCS vs. the Qaanaaq-based PCN data set performs better than either of the two Vostok-based PCS vs. Qaanaaq-based PCN indices. Along with the nice (but uncertain) quality performance presented in Figure 5a, c, and $\mathrm{d}$, the close inter-PC consistency between PCS (Dome-C) and PCN (THL) documents that the Dome-C magnetic data provide a fully qualified PCS index source. With a correlation coefficient of $R=0.800$ (Fig. 6d), the inter-PC consistency of Dome-C PCS versus Resolute PCN is better than the Vostok
PCS-Qaanaaq PCN relation whether in the IAGA or in the DMI version.

The last two rows in Table 4 display the intra-PC correlation between PCN index values based on Resolute and Qaanaaq data, respectively. For the epoch 2009-2016, the correlation coefficient is 0.841 (data not shown), which is close to the value $R=0.865$ shown in Figure $3 \mathrm{~b}$ and listed in the bottom row of Table 4 for the epoch 1997-2009 discussed in Section 4.1.

\subsection{Example case of application of PCS indices based on Dome-C data}

It is considered important for the reliability of PC index values both for scientific use of data series and for operational real-time space weather services, to have the ability to contrast the two independent PCS indices to each other or to have one substituted for the other if need arises.

For an example case, magnetic observations from Vostok through 2010-2011 are considered. The $X$ - and $Y$-component 

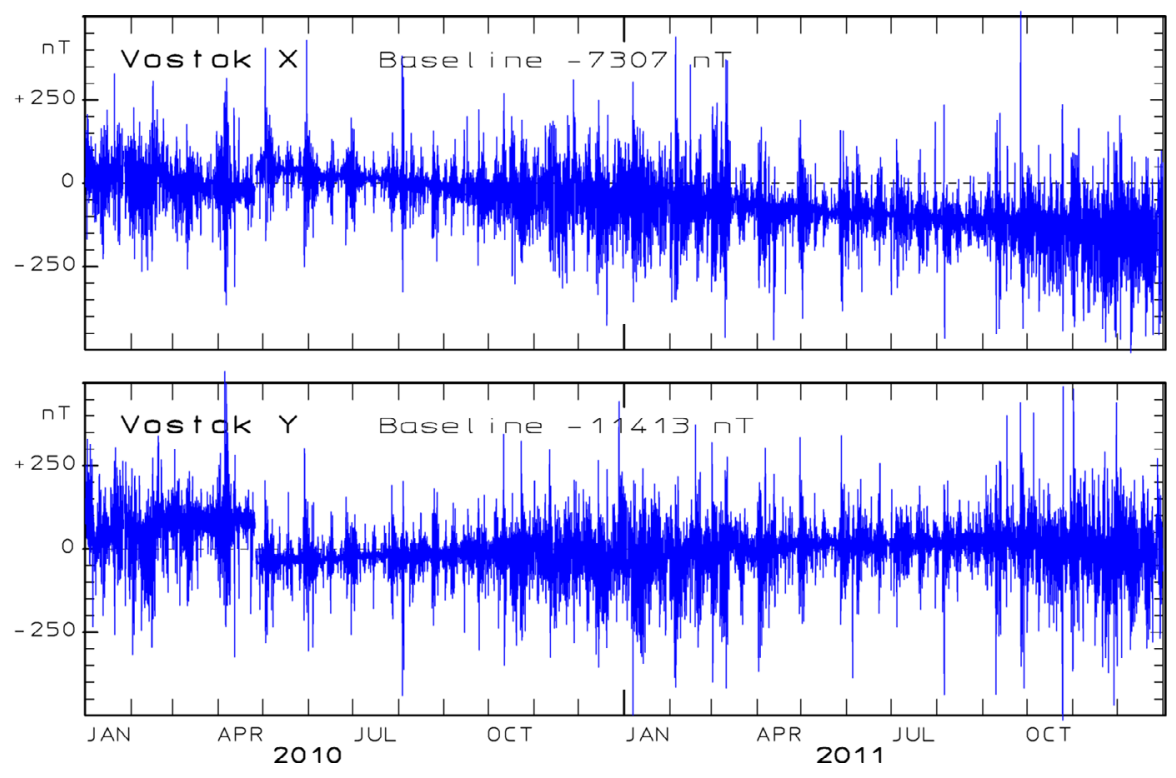

Fig. 7. Display of the $X$ - and $Y$-components of the geomagnetic field at Vostok through 2010-2011. The baselines in the plot are maintained at the constant levels noted in the diagrams. Data from 2010 are from http://pcindex.org, while data from 2011 are from http://intermagnet.org.

hourly average values are presented in Figure 7. The data for 2010 were supplied by the file "IAGA-Vostok-2010" from http://pcindex.org, while the values from 2011 are "definitive" INTERMAGNET data from http://intermagnet.org

From Figure 7 several irregularities are observed. There are jumps in the real base levels on 26 April, 2010, seen in the $X$ and (particularly) in the $Y$-component level upon a short disruption between 00:00 and 08:30 UT. Such base level jumps are not difficult to handle in post-event processing, but for realtime operations, the derived $\mathrm{PC}$ index values could be seriously affected for a while until the $Q L$ is adjusted to the new value.Another feature is the gradual decline through 2011 in the real base level for the $X$-component presented in the plot. Whether the decline is related to the long term (secular) variations in the Earth's field or caused by changes in the instrument or its base on the ice cap, the PC index program should be capable of processing the data appropriately. However, the PCS data available from http://pcindex.org are corrupted throughout most of 2011. Figure $8 \mathrm{~b}$ presents an example for July 2011 from a download of PC index values on 23 April 2017.

In the IAGA-Vostok PCS data (from http://pcindex.org) presented in Figure $8 \mathrm{~b}$, the strong daily variations distinguish these data from the PCS values derived from Vostok and Dome-C data by the DMI procedure. Note, in particular, the variations seen through the intervals from 16 to 18 and 28-30 July where the $E_{M}$ values are low. The PCS-DMI values are also low in agreement with the calm solar wind conditions, while the PCS-IAGA values oscillates between approximately -1 and $+2 \mathrm{mV} / \mathrm{m}$ through each day. These variations are most likely caused by poor handling of the base level $\left(\mathbf{F}_{B L}\right)$ included in the quiet level $(Q L)$ from which the disturbances represented in the PC indices are counted. According to equation (5), the effect of a base level error $\left(\Delta \mathbf{F}_{B L}\right)$ on the PC index would be:

$$
\Delta P C=\Delta \mathbf{F}_{B L, P R O J} / \alpha \text {. }
$$

The projection by equation (2) to the optimum direction generates a daily sine-like variation in the PCS index as the projection angle (Eq. (1)) varies through $360^{\circ}$ during the day. The amplitude is modulated by the daily variations in the slope value $(\alpha)$, which is also seen in panel b of Figure 8.In the more disturbed intervals, the proper PCS values come on top of the oscillations. Note in addition from panels $\mathrm{c}$ and $\mathrm{d}$ of Figure 8 the close correspondence between the PCS values derived by the DMI methods from Dome-C and Vostok observations, respectively.

\section{Discussions}

The PC indices are meant to monitor the transpolar forward convection intensities (Troshichev et al., 2006). The index quality is degraded if the location of the observatory that supplies the basic magnetic data moves outside the polar forward convection belt, for instance, during the daily rotation, at seasonal displacements of the belt, or during strong transverse IMF $B_{Y}$ conditions. Thus, a position very close to the magnetic pole, on the average, provides the best data basis. A position near the magnetic pole also diminishes the risk that poleward expanding substorms might disturb the data. Furthermore, the disturbance magnetic vector from the ring currents generated during magnetic storms would be nearvertical at the pole and, therefore, could not affect the horizontal components from which the $\mathrm{PC}$ indices are derived.

Reverse convection events during NBZ conditions might also be considered. They maximise in occurrence frequency and intensity in the summer season and in a relatively narrow region close to noon in-between the cusp and the pole (Stauning et al., 2002). They are particularly intense at locations where solar and geomagnetic noon are coincident. During reverse convection the projected magnetic disturbances (cf. Eq. (2)) are negative while the merging electric fields are always positive (cf. Eq. (3)). If included in the calculations of 

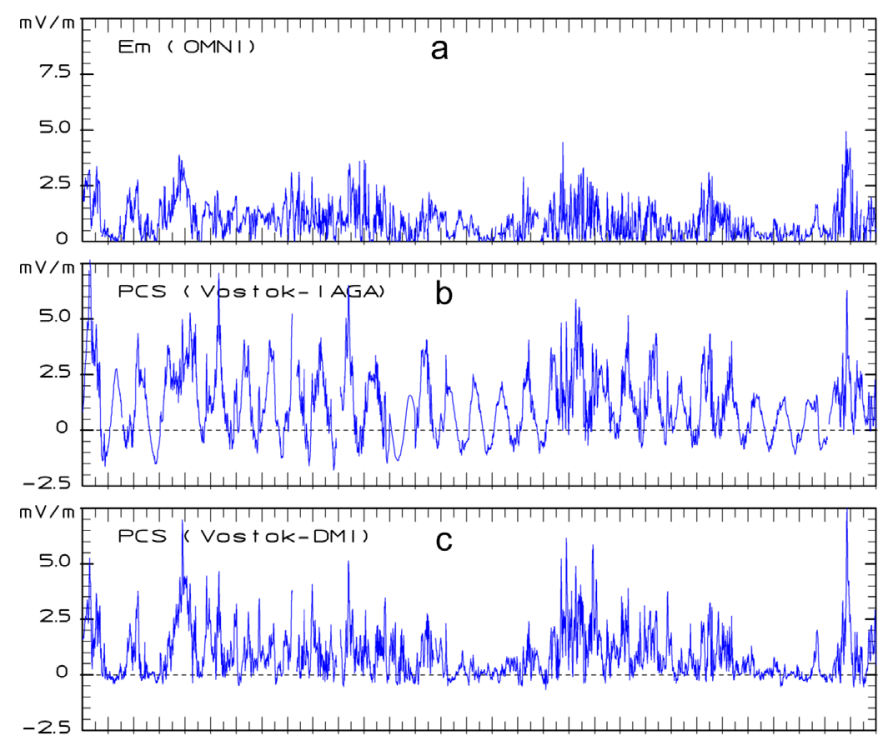

-2 .

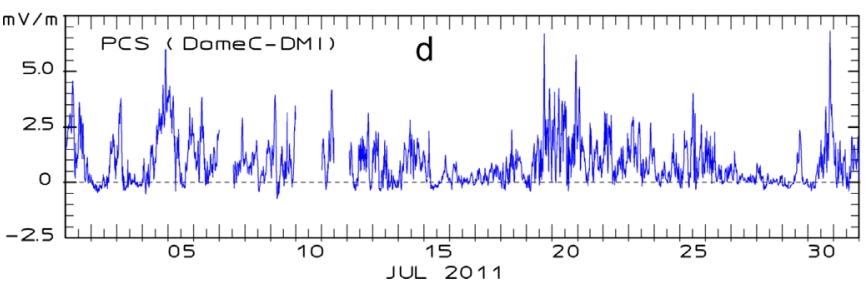

Fig. 8. From top of the diagram display of (a) the solar wind electric field, $E_{M}$, derived from OMNIweb data, (b) PCS index values (http:// pcindex.org) derived from Vostok magnetic data by the IAGAendorsed procedure, (c) PCS index values derived from Vostok data and (d) PCS values derived from Dome-C data by DMI methods (Stauning, 2016).

calibration parameters $(\alpha, \beta, \phi)$, they add anti-correlated samples that blur the estimates of optimum angles and make the regression generate larger slopes and more negative intercept values (Stauning, 2013c, 2015). The large temporal and seasonal variations in reverse convection conditions are then transferred to the calibration parameters and further on to index values thereby deteriorating PC index quality.

From Figure 2 and Table 2, it is seen that the OMNI PCN data series has the largest spread $\left(\Delta E_{C}=67 \%\right)$ among the presented index versions. Here, the summer daytime $E_{C}(\mathrm{sd})$ value is less than half the winter night value, $E_{C}(\mathrm{wn})$, which implies early saturation of index values. Thus, for summer daytime cases average $\mathrm{PCN}$ index values are reduced to half the corresponding $E_{M}$ values already at $E_{M}=E_{C}(\mathrm{sd}) \cdot \sqrt{ } 3=7 \mathrm{mV} / \mathrm{m}$. The low $E_{C}$ value in the summer season is most likely caused by the frequent occurrence of strong reverse convection events at daytime in the summer seasons during the solar maximum interval (19771980) used by Vennerstrøm (1991) for the derivation of index calibration parameters (cf. Tab. 1). For the epochs of data used for deriving calibration parameters for the AARI and IAGA index versions, the relative amounts of reverse convection events are less, the differences $\left(\Delta E_{C}=40\right.$ and $\left.38 \%\right)$ between average winter night and summer day indices are smaller, and the $E_{C}$ values are larger. The procedure used to derive calibration parameters in the DMI version omits reverse convection samples leading to still smaller differences $\left(\Delta E_{C}=15 \%\right)$ between winter night and summer day average PCN index values, and also to still larger $E_{C}$ values.

For the selection of procedure to be used for deriving index values from new observatory locations, the primary concern has been to ensure uniformity of methods. In addition, the quality graduation established through Figure 2 and Tables 2 and 4 has been considered in order to present the new potential index versions in the best possible way. These concerns have guided to the selection of the DMI procedure documented in Stauning (2016). The issues in the OMNI, AARI, and IAGA index procedures that may deteriorate $\mathrm{PC}$ index quality were discussed in Stauning (2013a, 2013c and 2015) and shall not be further elaborated here.

The DMI index procedures (Stauning, 2016) were developed on basis of the principles published in Troshichev et al. (2006). In most respects the methods are similar to the IAGA-endorsed procedure and use the same data epoch for derivation of the index scaling parameters $(\alpha, \beta, \phi)$. The DMI procedure uses the "solar rotation weighted" (SRW) $Q D C$ method (Stauning, 2011) to derive the reference level from which disturbance amplitudes are counted. The SRW "final" $Q D C$ values are derived from smoothed weighted averages of quiet samples from within an interval of 40 days before and after the day in question. The SRW method might use past data only (preceding 40 days) to derive a "real-time" $Q D C$ for any actual day. In a test on Qaanaaq data from 2002, the maximum index differences were $\triangle \mathrm{PCN}<0.5 \mathrm{mV} / \mathrm{m}$ between "final" and "real-time" PC indices.

The documentation (Stauning, 2016) holds additional descriptions of a "no- $Q D C$ " derivation procedure. A seasonally varying $Q D C$ averaged over the solar 11 year cycle could be implemented through the PC index calibration parameters, notably the intercept coefficient, $\beta$. For PCN indices derived throughout the solar maximum year 2002, the peak differences were below $1 \mathrm{mV} / \mathrm{m}$ in the PCN index values. This option using calibration parameters derived without $Q D C$ s was used for the additional "no- $Q D C$ " $\mathrm{PCN}$ values based on Resolute data presented in Figure 4.

While the finalizing PC index procedures with full $Q D C$ derivation are considered optimal for science and most appropriate for qualification of index versions, the real-time "no-QDC" method could be useful for "quick-look" space weather monitoring applications and for situations, where past data for $Q D C$ calculations are unavailable. The "real-time" index procedure with $Q D C$ derivation on past data is more robust to base level changes than the "no- $Q D C$ " version and is recommended for most space weather monitoring applications.

\section{Summary}

PC indices based on geomagnetic observations from PC stations are constructed to monitor the transpolar convection caused by the impact of the solar wind onto the magnetosphere and scaled with respect to the solar wind merging electric field $\left(E_{M}\right)$ to make the index values independent of observatory local time, season and location.

In order to characterize the range of $\mathrm{PC}$ indices for space weather purposes, the index level could be related, based on earlier works, to geophysical disturbances characterized by the auroral electrojet index, AE, the planetary magnetic distur- 
bance index, Kp, and the ring current disturbance index, Dst. PC index levels to characterize geomagnetic storms, substorm onsets, and alert conditions for power grids near the auroral zone, were summarized in Section 2.2.

The variation of average PC index values vs. the merging electric field, $E_{M}$, has been given a functional form depending on a single parameter, $E_{C}$. The spread, $\Delta E_{C}$, between values of $E_{C}$ derived for ensembles of index values grouped for different local time and seasonal conditions is thus a quality parameter and should take small values. The magnitude of $E_{C}$ is a secondary quality parameter to indicate index saturation properties and should be large. The interhemispheric correlation (R) between PCN and PCS index values, used to describe the degree of dependence on location, should take high values. Using the quality assessment scheme on some of the current PC index series has provided values for the spread between winter nights and summer days and the average magnitude of the distribution function parameters, as well as values for the interhemispheric correlations. The values are summarized in tables (Tabs. 2 and 4).

PCN and PCS index values derived from data supplied from the observatories at Resolute Bay in Canada and Dome-C in Antarctica, respectively, complies well with the established quality criteria. Their quality parameters $\left(\Delta E_{C}, E_{C}\right.$, and R) take values at the best end of the quality parameter ranges. The Resolute Bay location approximately 2 degree CGM latitude equatorward of Qaanaaq is considered a little inferior compared to the PCN standard location at Qaanaaq. The Dome-C location at the CGM pole is superior to the position of Vostok for the PCS index.

An example case from 13 March 1989 has demonstrated that PCN indices derived from Resolute Bay magnetometer data, within Canada a local source, could have given around $6 \mathrm{~h}$ early warning of the build up of the extraordinarily strong substorm that caused the Quebec power outage event.

An example case based on alternative PCS indices derived from Dome-C observatory data has shown that the PCS values based on Vostok data and supplied through the web portal http://pcindex.org are corrupted throughout most of 2011.

\section{Conclusions}

- The presented quality analyses have shown that observations from the INTERMAGNET-grade magnetic observatories at Resolute Bay in Canada and Dome-C in Antarctica are fully qualified to become alternative sources for PCN and PCS indices, respectively;

- The presented examples have demonstrated the usefulness of using multi-station PC index sources for ensuring credibility and operational reliability in applications using PC indices for analyses or monitoring of space weather conditions.

\section{Data availability}

Near real-time PC index values and PCN and PCS index series derived by the IAGA-endorsed procedure are available through the web site: http://pcindex.org. Data used in the paper were downloaded on 23 April 2017. The web site, furthermore, holds PCN and PCS index coefficients. $Q D C$ values are not included. The web site includes the document "PC Index" (Troshichev, 2011).

Geomagnetic data from Qaanaaq, Resolute and Dome-C were supplied in part from the INTERMAGNET data service center at http://intermagnet.org, in part from the DTU Space $\mathrm{ftp}$ data server at ftp://ftp.space.dtu.dk/WDC/, in part from the WDC service for Geomagnetism, Edinburgh, available at http://www.wdc.bgs.ac.uk

The observatory in Qaanaaq is managed by the Danish Meteorological Institute, while the magnetometer there is operated by DTU Space, Denmark. The Vostok observatory is operated by the Arctic and Antarctic Research Institute in St. Petersburg, Russia. The Dome-C observatory is managed by Ecole et Observatoire des Sciences de la Terre (France) and Istituto Nazionale di Geofisica e Vulcanologia (Italy), while the observatory at Resolute Bay is operated by the Geological Survey of Canada.

Geomagnetic data from Vostok were supplied in part from the web portal http://pcindex.org, in part from the INTERMAGNET portal http://intermagnet.org, and in part from the Arctic and Antarctic Research Institute in St. Petersburg, Russia (at http://geophys.aari.ru).

Solar wind OMNI BSN data from combined ACE, WIND, IMP8, and Geotail interplanetary satellite measurements and PCN data in the "OMNI" version were provided from the OMNIweb data service at Goddard Space Flight Center, NASA at http://omniweb.gsfc.nasa.gov.

The PCN and PCS data in the "AARI" version were supplied from the Arctic and Antarctic Research Institute in St. Petersburg, Russia (at http://geophys.aari.ru).

The "DMI" PC index version is documented in the report SR-16-22 (Stauning, 2016) available at the DMI web site: http://www.dmi.dk/fileadmin/user_upload/Rapporter/TR/ 2016/SR-16-22-PCindex.pdf.

Acknowledgments. The staffs at the observatories in Qaanaaq (Thule), Vostok, Resolute Bay and Dome-C, and their supporting institutes are gratefully acknowledged for providing high-quality geomagnetic data for this study. The excellent service at the OMNIweb data center at GSFC, NASA, to provide processed solar wind satellite data, the efficient provision of geomagnetic data from the INTERMAGNET data center, and the nice performance of the PC index portal are greatly appreciated. The author gratefully acknowledges the good collaboration and many rewarding discussions with Drs. O. A. Troshichev and A. S. Janzhura at the Arctic and Antarctic Research Institute in St. Petersburg, Russia.

The editor thanks Eftyhia Zesta and two anonymous referees for their assistance in evaluating this paper.

\section{References}

Chambodut A, Di Mauro D, Schott JJ, Bordais P, Agnoletto L, Di Felice P. 2009. Three years continous record of the Earth's magnetic field at Concordia station (Dome-C, Antarctica). Annals of Geophysics 52: 15-24.

Di Mauro D, Cafarella L, Lepidi S, Pietrolungo M, Alfonsi L, Chambodut A. 2014. Geomagnetic polar observatories: the role of Concordia station at Dome C, Antarctica. Annals of Geophysics 57: 6. DOI:10.4401/ag-6605. 
Huang C-S., Sofko GJ, Koustov AV, André DA, Ruohoniemi JM, Greenwald RA, Hairston MR. 2000. Evolution of ionospheric multicell convection during northward interplanetary magnetic field with $\left|B_{Z} / B_{Y}\right|>1$. J Geophys Res 105: 27095-27107.

Janzhura AS, Troshichev OA. 2008. Determination of the running quiet daily geomagnetic variation. J Atmos Solar-Terr Phys 70: 962-972. DOI:10.1016/j.jastp.2007.11.004.

Janzhura AS, Troshichev OA. 2011. Identification of the IMF sector structure in near-real time by ground magnetic data. Ann Geophys 29: 1491-1500. DOI:10.5194/angeo-29-1491-2011.

Janzhura A, Troshichev OA, Stauning P. 2007. Unified PC indices: relation to the isolated magnetic substorms. J Geophys Res 112: A09207. DOI: 10.1029/2006JA012132.

Kan JR, Lee LC. 1979. Energy coupling function and solar windmagnetosphere dynamo. Geophys Res Lett 6: 577-580. DOI:10.1029/GL006i007p00577.

Papitashvili VO, Rasmussen O. 1999. Effective area for the northern polar cap magnetic activity index. Geophys Res Lett 26: 2917 2920. DOI:10.1029/1999GL003611.

Papitashvili VO, Gromova LI, Popov VA, Rasmussen O. 2001. Northern Polar Cap magnetic activity index PCN: effective area, universal time, seasonal and solar cycle variations. DMI Scientific Report SR 01-01. ISSN: 0905-3263, ISBN: 87-7478-432-3. Available at http://www.dmi.dk/fileadmin/Rapporter/SR/sr01-01. pdf

Ridley AJ. 2005. A new formulation for the ionospheric cross polar cap potential including saturation effects. Ann Geophys 23: $3533-$ 3547. DOI:10.5194/angeo-23-3533-2005.

Stauning P. 2007. A new index for the interplanetary merging electric field and the global geomagnetic activity: application of the unified Polar Cap (PCN and PCS) indices. AGU Space Weather 5: S09001. DOI:10.1029/2007SW000311.

Stauning P. 2011. Determination of the quiet daily geomagnetic variations for polar regions. J Atm Solar-Terr Phys 73: 2314-2330. DOI:10.1016/j.jastp.2011.07.004.

Stauning P. 2012. The Polar Cap PC indices: relations to solar wind and global disturbances. In: Marian L, ed. Exploring the solar wind. InTech Publ. ISBN: 978-953-51-0339-4. DOI: 10.5772/37359.

Stauning P. 2013a. Comments on quiet daily variation derivation in: "Identification of the IMF sector structure in near-real time" by ground magnetic data by Janzhura and Troshichev (2011). Ann Geophys 31: 1221-1225. DOI:10.5194/angeo31-1221-2013.

Stauning P. 2013b. Power grid disturbances and polar cap index during geomagnetic storms. J Space Weather Space Clim 3: A22. DOI:10.1051/swsc2013044.

Stauning P. 2013c. The Polar Cap index: a critical review of methods and a new approach. J Geophys Res Space Phys 118: 5021-5038. DOI: 10.1002 /jgra.50462.

Stauning P. 2015. A critical note on the IAGA-endorsed Polar Cap index procedure: effects of solar wind sector structure and reverse polar convection. Ann Geophys 33: 1443-1455. DOI:10.5194/ angeo-33-1443-2015. www.ann-geophys.net/33/1443/2015.
Stauning P. 2016. The Polar Cap (PC) index: derivation procedures and quality control. DMI Scientific Report SR-16-22. Available at: http://www.dmi.dk/fileadmin/user_upload/Rapporter/TR/2016/ SR-16-22-PCindex.pdf

Stauning P, Christiansen F, Watermann J, Christensen T, Rasmussen O. 2002. Mapping of field-aligned current patterns during northward IMF. In: Reigber C, Lühr H, Schwintzer P, eds. First CHAMP Mission results for gravity, magnetic and atmospheric studies. Berlin: Springer-Verlag, 353-360, DOI:10.1007/ 978-3-540-38366-6.

Stauning P, Troshichev OA, Janzhura A. 2008. The Polar Cap (PC) indices. Relations to solar wind parameters and global magnetic activity. J Atmos Solar-Terr Phys 70: 2246-2261. DOI:10.1016/j. jastp.2008.09.028.

Troshichev OA. Polar Cap (PC) index. 2011. Available at: http:// geophys.aari.ru/Description.pdf or http://pcindex.org.

Troshichev OA, Andrezen VG. 1985. The relationship between interplanetary quantities and magnetic activity in the southern polar cap. Planet Space Sci 33: 415-419, DOI: 10.1016/0032-0633(85) 90086-8.

Troshichev OA, Janzhura A. 2009. Relationship between the PC and $\mathrm{AL}$ indices during repetitive bay-like magnetic disturbances in the auroral zone. J Atmos Solar-Terr Phys 71: 1340-1352. DOI: 10.1016/j.jastp.2009.05.017

Troshichev OA, Janzhura A, Space weather monitoring by groundbased means, Springer-Verlag, Berlin, Heidelberg, 2012. ISBN: 978-3-642-16802-4. DOI:10.1007/978-3-642-16803-1.

Troshichev OA, Andrezen VG, Vennerstrøm S, Friis-Christensen E. 1988. Magnetic activity in the polar cap - a new index. Planet Space Sci 36: 1095-1102. DOI: 10.1016/0032-0633(88)90063-3

Troshichev OA, Janzhura A, Stauning P. 2006. Unified PCN and PCS indices: method of calculation, physical sense and dependence on the IMF azimuthal and northward components. J Geophys Res111: A05208. DOI:10.1029/2005JA011402. (note correction in Troshichev et al., 2009)

Troshichev O, Janzhura A, Stauning P. 2009. Correction to Unified PCN and PCS indices: method of calculation, physical sense, and dependence on the IMF azimuthal and northward components. $J$ Geophys Res 114: A11202. DOI:10.1029/2009JA014937.

Troshichev OA, Somarkov DA, Janzhura A. 2011. Relation of PC index to the geomagnetic storm Dst variation. J Atmos Solar-Terr Phys 73: 611-622. DOI:10.1016/j.jastp.2010.12.015.

Troshichev OA, Sormakov DA, Janzhura A. 2012. Relations between $\mathrm{PC}$ index and substorm (AL) and storm (SYM, ASYM) indices under conditions of the steadily high solar wind energy input into the magnetosphere. Adv Space Res 49: 872-882. DOI:10.1016/j. asr.2011.12.011.

Troshichev O, Podorozhkina NA, Sormakov DA, Janzhura A. 2014. $\mathrm{PC}$ index as a proxy of the solar wind energy that entered into the magnetosphere: 1. Development of magnetic substorms. J Geophys Res Space Phys 119: 6521-6540. DOI:10.1002/2014JA019940.

Vennerstrøm $\mathrm{S}$, The geomagnetic activity index $\mathrm{PC}, \mathrm{PhD}$ Thesis, Scientific Report 91-3, Danish Meteorological Institute, 1991, 105 p.

Cite this article as: Stauning P. 2018. Multi-station basis for Polar Cap (PC) indices: ensuring credibility and operational reliability. J. Space Weather Space Clim. 8: A07 